\title{
Primeiro registro de Aganisia fimbriata (Orchidaceae: Zygopetalinae) para a Região Centro-Oeste do Brasil
}

\author{
๑Dathias Erich Engels ${ }^{1,5}$, Lilien Cristhiane Ferneda Rocha ${ }^{2}$, Climbiê Ferreira Hall ${ }^{3}$ e Ana Kelly Koch ${ }^{4}$
}

Recebido: 27.08.2017; aceito: 20.04.2018

\begin{abstract}
First record of Aganisia fimbriata (Orchidaceae: Zygopetalinae) for the Central-West region of Brazil). Aganisia fimbriata is a South American species of orchid found in Brazil, Guyana, Peru, Suriname, and Venezuela. In Brazil, it is registered in the States of Acre, Amazonas, Maranhão, Pará and now for the first time in the Central-West Region, State of Mato Grosso. This species was found in Mato Grosso State as hemiepiphyte, in paludose forest at the margins of a tributary stream of the Teles Pires river, in Evergreen Seasonal Forest on the southern edge of the Amazonian domain. This new record represents the southern distribution limit of the species in Brazil. We present a description, photographs, and comments on taxonomy, and distribution of the species.
\end{abstract}

Keywords: Amazon, hemiepiphyte, Neotropics, orchids, Teles Pires river

RESUMO - (Primeiro registro de Aganisia fimbriata (Orchidaceae: Zygopetalinae) para a Região Centro-Oeste do Brasil). Aganisia fimbriata é uma espécie Sul-Americana de orquídea que ocorre no Brasil, Guiana, Peru, Suriname e Venezuela. No Brasil é registrada nos Estados do Acre, Amazonas, Maranhão, Pará, e agora pela primeira vez na região Centro-Oeste, Estado de Mato Grosso. Foi encontrada no Estado de Mato Grosso como hemiepífita, em floresta paludosa às margens de pequeno riacho tributário do rio Teles Pires, em Floresta Estacional Sempre Verde na borda sul do Domínio Amazônico. Este novo registro corresponde ao limite austral de distribuição geográfica da espécie no Brasil. Apresentam-se descrição da espécie, prancha fotográfica, comentários taxonômicos e a distribuição da espécie.

Palavras chave: Amazônia, hemiepífita, orquídea, região neotropical, rio Teles Pires

O gênero neotropical Aganisia Lindl. (Epidendroideae, Cymbidieae, Zygopetalinae) ocorre desde Trindade e Tobago e norte da América do sul (Venezuela e Guianas) até a Bolívia e Brasil (Pupulin 2009). O gênero é representado por ervas holoepífitas e hemiepífitas que ocorrem associadas a ambientes com água, sendo representado por três espécies: $A$. cyanea (Schltr.) Rchb.f.; A. fimbriata Rchb.f. e A. pulchella Lindl. (Meneguzzo et al. 2015, Govaerts 2017).

As filogenias moleculares de Whitten et al. (2005), mostraram que a subtribo Zygopetalinae é monofilética e possui dois grandes grupos: clado Huntleya (com pseudobulbos ausentes ou reduzidos e folhas conduplicadas) e grado Zygopetalum (com pseudobulbos conspícuos e folhas convolutas e plicadas). No grado Zygopetalum há diversos subgrupamentos menores, entre eles o complexo Aganisia, que é constituído pelos gêneros Aganisia, Cheiradenia, Koellensteinia, Otostylis e Paradisanthus (ver Meneguzzo et al. 2015).

Durante o resgate de Flora da Usina Hidrelética Colíder, foi coletado material de Aganisia fimbriata, que corresponde ao primeiro registro para o Estado de Mato Grosso, bem como, para a região Centro-Oeste brasileira.

O material coletado foi herborizado segundo as técnicas usuais da taxonomia vegetal (Fidalgo \& Bononi 1989) e depositado no Herbário MBM, acrônimo de acordo com Thiers (continuamente atualizado). Para identificação, nomenclatura

1. Assessoria Técnica Ambiental Ltda., Rua Marechal José Bernardino Bormann, 821, Batel, 80730-350 Curitiba, Paraná, Brasil

2. Juris Ambientis Consultores S S Ltda., Rua Humberto Carta, 96, Hugo Lange, 80040-150 Curitiba, Paraná, Brasil

3. Museu Paraense Emílio Goeldi, Campus de Pesquisa, Coordenação de Botânica, Programa de Capacitação Institucional, , Av. Perimetral, 1901, Terra Firme, 66077-830 Belém, Pará, Brasil

4. Universidade do Estado de Mato Grosso, Herbário da Amazônia Meridional, MT 208, Km 146, s/n, Jardim Tropical, 78580-000 Alta Floresta, Mato Grosso, Brasil

5. Autor para correspondência: mathiasengels@hotmail.com 
e distribuição geográfica foram consultadas as bibliografias Pabst \& Dungs (1977), Meneguzzo et al. (2015); BFG (2015); Flora do Brasil 2020 em construção (2017); e Govaerts (2017). Termos morfológicos gerais seguem Radford et al. (1974) e Harris \& Harris (1994); para morfologia específica de Orchidaceae seguem Dressler (1993) e Pupulin (2009).

No presente estudo são fornecidas a descrição, prancha fotográfica, a distribuição geográfica e comentários taxonômicos e ecológicos de A. fimbriata.

\section{Taxonomia}

Aganisia fimbriata Rchb.f., Gard. Chron., n.s., 2: 452. 1874. Tipo: Guiana. Demerara: ex hort., s.d., Sillem s.n. (lectótipo, designado por Meneguzzo et al. 2015, W-R 40596).

\section{Figura 1}

Erva hemiepífita. Rizoma 120-180 × 0,5-1 cm, alongado, achatado sobre o substrato, $5-8 \mathrm{~cm}$ entre pseudobulbos. Pseudobulbos 4,5-5 × 1,4-1,8 cm, lanceoloides, compressos lateralmente, heteroblásticos, unifoliados, verdes. Folha peciolada; pecíolo 2,4-4 × 0,3 cm, verde; limbo 40,7-43 × 4,3-5,2 cm, elíptico a estreito-elíptico, plicado, com 5 nervuras principais, adaxialmente impressas e abaxialmente proeminentes, verde, levemente discolor. Inflorescência axilar, racemo simples, 5-8-flora; pedúnculo $11,5-14 \times 0,2 \mathrm{~cm}$, subcilíndrico, verdeacastanhado; brácteas do pedúnculo 1,1-1,4×0,6 cm, amplectivas, estreito-triangulares, base truncada, margem inteira, ápice agudo, acastanhadas; raque 5-8,4 × 0,1-0,2 cm, subcilíndrica, verde-acastanhada; bractéolas 1,1-1,3 $\times 0,2-0,3 \mathrm{~cm}$, estreito-triangulares, base truncada, margem inteira, ápice agudo, verdeacastanhadas. Flores ressupinadas; ovário + pedicelo 1,2-1,4 $\times 0,15 \mathrm{~cm}$, cilíndrico, sulcado na soldadura dos carpelos, lilás-azulado-esverdeado; sépalas e pétalas lilás-azuladas, apresentando nervuras adaxialmente alvas; sépala dorsal 2-2,2 $\times 0,4 \mathrm{~cm}$, elíptico-obovalada, base aguda, margem inteira, ápice obtuso; sépalas laterais 2,1-2,3 × 1,5 cm, elípticas, base cuneada, margem inteira, ápice obtuso; pétalas 1,9-2 $\times 1,1-1,3 \mathrm{~cm}$, elíptico-obovaladas, base aguda, margem inteira, ápice obtuso; labelo ca. 1,6×1,6 cm, trilobado, dotado de um calo central; lobos laterais ca. $1 \mathrm{~mm}$ compr., deltados, ápice agudos, castanhopálidos; lobo central ca. $1 \times 1,6 \mathrm{~cm}$, largo-obovalado, navicular, base obtusa, margem fimbriada, ápice arredondado, lilás-alvacento com fímbrias mais escuras; fímbrias 1-3 mm compr., afiladas; calo ca. $2 \times 3 \mathrm{~mm}$, deltoide, castanho-pálido. Coluna ca. $1,4 \times 0,3 \mathrm{~cm}$, subclavada, ventralmente achatada, levemente arqueada, com um par de alas na margem e adjacentes à região do estigma, alva; alas da coluna ca. $4 \times 2 \mathrm{~mm}$, elípticas, ápice redondo, alvas. Antera ca. $3 \times 2,5 \mathrm{~mm}$, arredondada, ápice apiculado, alva. Polínias 4, em dois pares de tamanho desigual, as maiores ca. $1 \mathrm{~mm}$, obovaladas, compressas lateralmente, amarelas. Estipe ca. $0,25 \mathrm{~mm}$, quadrado, alvacento. Viscídio ca. $0,35 \mathrm{~mm}$, elíptico, alvacento. Frutos e sementes não vistas.

Material examinado: BRASIL. Mato Grosso: Itaúba, resgate de Flora da UHE Colíder (rio Teles Pires), Estrada de acesso para Lote $\mathrm{F}$ de supressão, fl., 30-I-2017, M.E. Engels \& A.S. Bezerra 4926 (MBM).

Aganisia fimbriata ocorre na Guiana, Suriname, Venezuela, Peru e Brasil (Meneguzzo et al. 2015; Govaerts 2017). No Brasil é conhecida para a região Norte, nos Estados do Acre, Amazonas e Pará, com possíveis ocorrências para o Amapá e Rondônia, e para a região Nordeste no Maranhão (Meneguzzo et al. 2015, BFG 2015, Flora do Brasil 2020 em construção, 2017), sendo um novo registro para a região CentroOeste, no Estado de Mato Grosso, correspondendo ao limite austral da espécie no Brasil.

Devido à ampla distribuição no norte da América do Sul, A. fimbriata tem seu estado de conservação classificado como Pouco Preocupante [LC B1 + B2] segundo os critérios da IUCN (2016). Apesar de uma ampla consulta a herbários e trabalhos de campo realizados em diversas partes do Mato Grosso em busca de espécies de Zygopetalinae, A. fimbriata foi registrada apenas no município de Itaúba, sendo classificada como Criticamente ameaçada [CR B1ab(iii) + B2ab(iii)] para o Estado do Mato Grosso, pela extensão de ocorrência menor que $100 \mathrm{~km}^{2}$.

Aganisia fimbriata foi encontrada em Mato Grosso como hemiepífita no subosque de floresta paludosa, às margens de pequeno riacho tributário do rio Teles Pires, em Floresta Estacional Sempre Verde, borda sul do Domínio Amazônico. Aparentemente esta espécie se comporta como hemiepífita primária, onde o desenvolvimento inicial ocorre no solo/serapilheira, posteriormente se dirigindo para um forófito. A ligação do caule entre solo/serapilheira e forófito pode permanecer ou desaparecer, dependendo do estágio de desenvolvimento do indivíduo. O caule é alongado e fortemente prostrado sobre o forófito, podendo chegar a até 1,8 $\mathrm{m}$ do solo. $\mathrm{Na}$ área onde foi encontrada é pouco frequente e floresce em janeiro e fevereiro. 


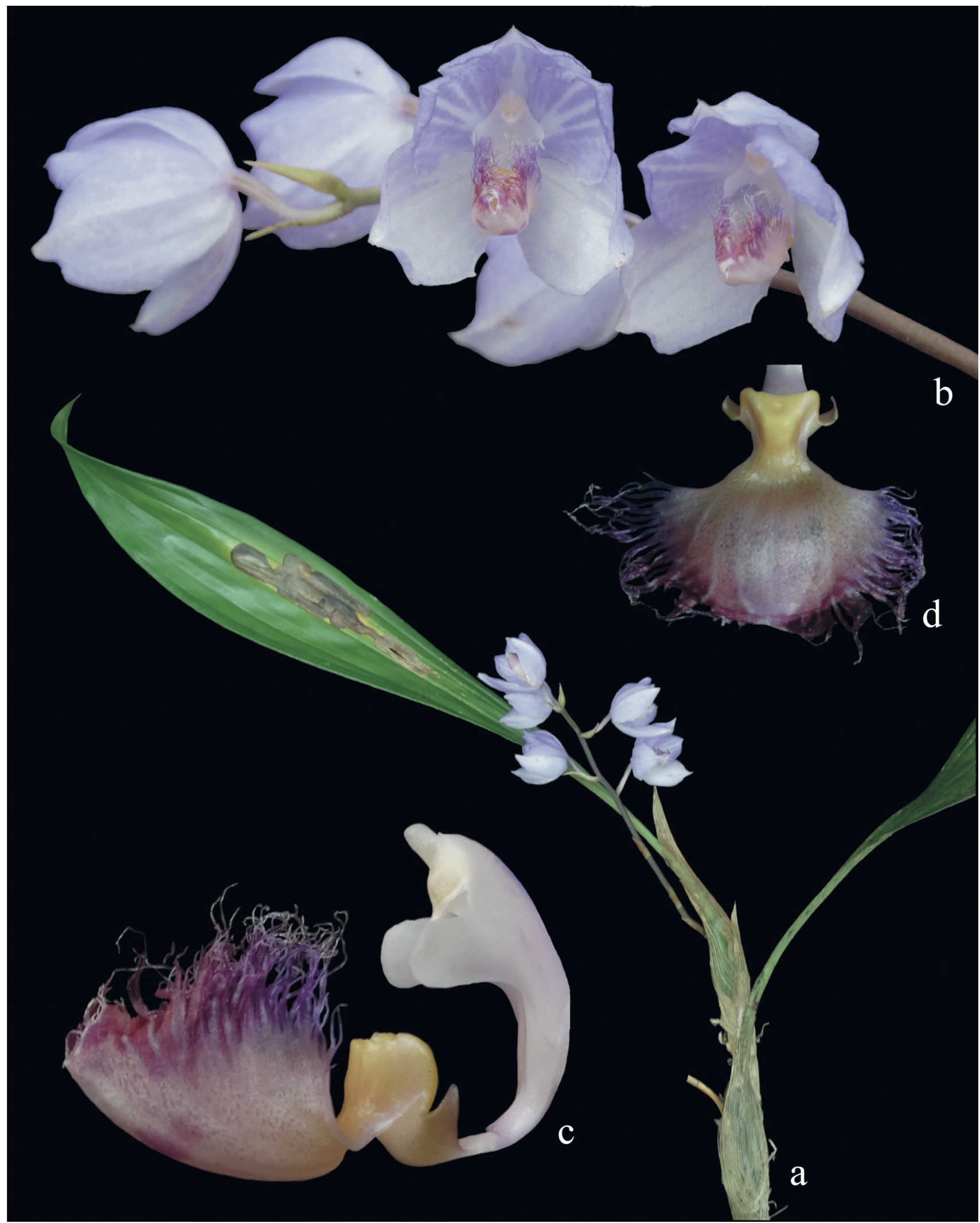

Figura 1. Aganisia fimbriata. a. Hábito. b. Inflorescência. c. Labelo e coluna (vista lateral). d. Labelo distendido (M.E. Engels \& A.S Bezerra 4926). Fotos: M.E. Engels.

Figure 1. Aganisia fimbriata. a. Habit. b. Inflorescence. c. Labellum and column (side view). d. Distended labellum (M.E. Engels \& A.S Bezerra 4926). Photos: M.E. Engels. 
Aganisia fimbriata é semelhante às outras espécies do gênero devido ao hábito hemiepifítico, rizomatoso; pseudobulbos cobertos por bainhas membranáceas secas; folhas plicadas; e flores com labelo unguiculado, trilobado, com lobos laterais pequenos e calo lamelado ereto. Porém, pode ser diferenciada por suas flores em tons de lilás ( $v s$. alvas em A. pulchella), e pelo lobo central do labelo com margem fimbriada ( $v s$. inteira a ondulada).

\section{Agradecimentos}

À Companhia Paranaense de Energia (COPEL) por permitir e incentivar a publicação dos dados aqui contidos. Ao Consórcio CIA Ambiental - Juris Ambientis e seus colaboradores. Ao CNPq pela bolsa do Programa de Capacitação Institucional (MPEG/ MCTI) concedida a CFH. À Adão da Silva Bezerra pela ajuda nos trabalhos de campo.

\section{Literatura citada}

BFG (The Brazil Flora Group). 2015. Growing knowledge: an overview of Seed plants diversity in Brazil. Rodriguésia 66: 1085-1113.

Dressler, R.L. 1993. Phylogeny and classification of the orchid family. Dioscorides Press, Portland.

Fidalgo, O. \& Bononi, V.L.R. 1989. Técnicas de coleta, preservação e herborização de material botânico. Reimpressão. Instituto de Botânica, São Paulo.

Flora do Brasil 2020 em construção. 2017. Orchidaceae. Jardim Botânico do Rio de Janeiro. Disponível em http:// www.floradobrasil.jbrj.gov.br/reflora/floradobrasil/ FB179 (acesso em 18-III-2017).
Govaerts, R. 2017. World Checklist of Orchidaceae. Facilitated by the Royal Botanic Gardens, Kew. Disponível em www.kew.org/wcsp/monocots (acesso em 18-III-2017).

Harris, J.G. \& Harris, M.W. 1994 Plant identification terminology - an illustrated glossary. Spring Lake Publishing, Spring Lake, Utah.

IUCN (Standards and Petitions Subcommittee). 2016. Guidelines for Using the IUCN Red List Categories and Criteria. Version 12. Prepared by the Standards and Petitions Subcommittee. Disponível em http:// www.iucnredlist.org/documents/RedListGuidelines.pdf (acesso em 7-XII-2016).

Meneguzzo, T.E.C., Baumgratz, J.F.A. \& van den Berg, C. 2015. Taxonomic studies in the Aganisia complex (Orchidaceae, Zygopetalinae). Phytotaxa 238: 1-39.

Pabst, G.F.J. \& Dungs, F. 1977. Orchidaceae Brasilienses II. Brucke-Verlag Kurt Schmersow, Hildesheim.

Pupulin F. 2009. Subtribe Zygopetalinae. In: A.M. Pridgeon, P.J. Cribb, M.W. Chase \& F.N. Rasmussen (eds.). Genera Orchidacearum. v. 5. Epidendroideae (Part Two). Oxford University Press, Oxford, pp. 456-546.

Radford, A.E., Dickison, W.C., Massey, J.R. \& Bell, C.R. 1974. Vascular Plant Systematics. Harper \& Row Publishers, New York.

Thiers, B. [continuously updated]. 2017. Index Herbariorum. Part I: The herbaria of the world. New York Botanical Garden. Disponível em from http:// sweetgum.nybg.org/science/ih/ (acesso em 21-X-2017).

Whitten, M.W., Williams, N.H., Dressler, R.L., Gerlach, G. \& Pupulin, F. 2005. Generic relationships of Zygopetalinae (Orchidaceae: Cymbidieae): combined molecular evidence. Lankesteriana 5: 87-107. 